\section{The spy at home}

\section{In brief}

- Devices with digital assistants and voice control, such as "smart speakers", are becoming more widespread in households where they are potentially eavesdropping on buyers in their most private spaces.

- The devices collect personal data and send it to the manufacturers. Non-transparent data analysis exacerbates the imbalance between suppliers and consumers.

- In future, digital assistance systems could manage the access to the (online) world.

- The assessment of this business model raises not only data protection issues, but also sociopolitical questions.

\section{What is it about?}

For a long time, voice control used to be a niche application, but it now appears to have become suitable for the mass market thanks to smart speakers. Globally, the number of so-called smart speakers sold per quarter has quadrupled year-on-year since 2016. Suppliers' sales are particularly high in the fourth quarter due to the Christmas period. There are more and more households in which one of the popular digital assistants can be found in such a speaker. Since the use of Alexa \& Co. at home has increased, their use has also increased on smartphones, despite such systems having been available on mobile devices for quite some time. The areas of application for these assistance systems are continuously expanding: by now, smart speakers are already being installed even at public authorities and in some hotel rooms. Cars, too, have integrated virtual assistants.

Alexa, Google Assistant, Siri, Cortana or Bixby try to support their users by answering questions, sending messages on command, doing the shopping, playing music, providing information about the weather, telling a joke or setting the alarm clock. The functionality of most of them can be extended with third-party software, e.g. when it comes to controlling devices in smart homes. This may not yet be without any problems; nevertheless all parties involved have great expectations for the future.

In addition to these tasks, voice control also offers great advantages for certain groups of people. Blind people or those with fine motor dysfunction benefit greatly from the possibility of voice input. For them, digital assistants can therefore enable participation in the digital world.

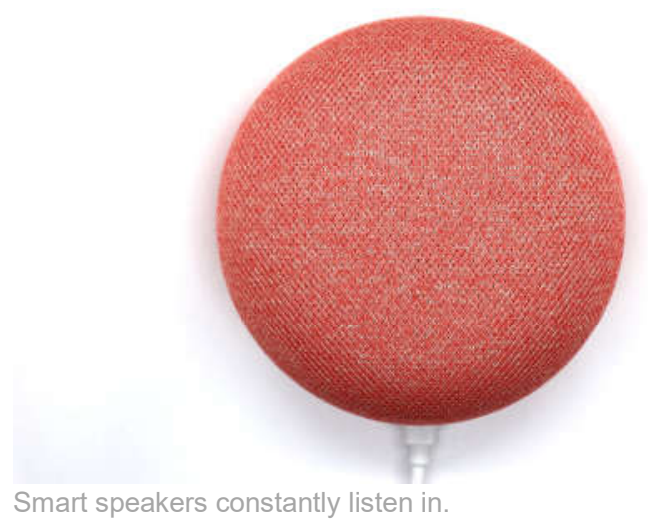

In order to perform these tasks, they need to maintain a connection to their manufacturers since speech recognition takes place in the manufacturer's cloud. Furthermore, they must constantly listen for the "wake word" that activates voice recording and analysis. In the past, it has been shown that the devices can mistakenly interpret even snippets of conversation as an activation phrase. Intentional and unintentional recordings create very precise profiles of every household: who lives there, how many people, when are they at home, what is being talked about, what interests do the residents have, what controllable devices are available, and much more. The possibility of linking metadata (place and time of the request, last request, etc.) with data from other sources, mainly the smartphone and/or the order history, also creates very precise individual profiles.

\section{Basic data}

$\begin{array}{ll}\text { Project title: } & \text { Digital Assistants } \\ \text { Project team: } & \text { Schaber, F, Krieger-Lamina, J., } \\ & \text { Peissl, W. } \\ \text { Duration: } & 08 / 2018-06 / 2019 \\ \text { Commissioned by: Federal Chamber of Labour }\end{array}$




\section{Key results}

Notwithstanding the differences between the providers, none of the products can presently be regarded as truly data protection-friendly products. All data is processed, stored and analysed centrally. In most cases, data is only deleted very late or not at all.

For the future, providers expect to see big business: conversational commerce or voice-based purchasing are to trigger a similar change as did the advent of e-commerce. The voice does not only identify the individual everywhere, but also his or her state of mind and health. Suitable products would then only be a question or command away.

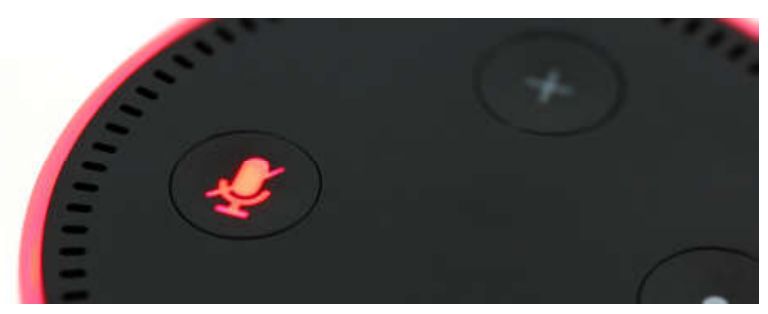

Data analysis offers great advantages to providers.

Data analysis also offers great advantages to providers in another area: the more (training) data is available for their algorithms, the better the systems will be, the more users will be attracted to them, the more third-party providers will want to connect with the platform, which in turn will convince more users to join the platform, and so on. In the absence of countermeasures, these network effects will not only lead to large providers' continuing growth, but also to competition being squeezed out of the market.

Already, many want to be part of this business in order to secure a share of the future market. If in the future one will be surrounded by networked objects and digital assistants that are always available and accessible via many different devices, it is likely that many tasks and requests will be handled through them. They will know when we communicate and with whom, where we spend our days, what interests us, and so on. These systems will literally know everything about us. On the other hand, they may respond and make suggestions based on the commercial interests of their manufacturers. It will be difficult or even impossible for users to know if and how they are being manipulated. Similar to the results of search engines, we will be presented with content that is particularly profitable for the provider. Each assistant will serve a different "ecosystem", suggest different mail-order companies, transport companies or holidays.

These assistance systems would be the gatekeeper between consumers, advertisers, retailers and producers. It would be difficult to control them in this position of power.

\section{What to do?}

Voice control and digital assistants will in all probability prevail on the market. Currently, it is mainly the providers of assistance systems who benefit from them, and not so much their customers. The collection and analysis of personal data should also, but not solely, be considered from a data protection point of view.

- The protection of privacy and other fundamental rights is essential in a liberal democratic society. Widespread use of these devices endangers privacy and with it the cornerstones of democracy. Politicians should therefore take a close look at what regulatory options are available, what resources are needed, what knowledge is still lacking and what needs to be researched.

- Providers of these systems might want to consider to also process data locally on the devices, collect or analyse only aggregated data, and consider more generally how they could improve their business through the competitive advantage of privacy-friendly product design, thereby complying more accurately with existing norms.

- Consumers should consider carefully whether digital assistants meet their expectations and whether the benefits compared to the disadvantages described justify their use. Should these considerations lead to the purchase of such a device, the deciding factor for the decision to purchase should be the relative best protection of privacy. Ultimately, this could motivate manufacturers to better follow the concept of privacy by design.

\section{Further reading}

Schaber, F., Krieger-Lamina, J., Peissl, W. (2019):

Digitale Assistenten, project report 01-2019, ITA: Vienna epub.oeaw.ac.at/ita/ita-projektberichte/2019-01.pdf

\section{Contact}

\section{Jaro Krieger-Lamina}

Email: tamail@oeaw.ac.at

Phone: +43(1)51581-6582

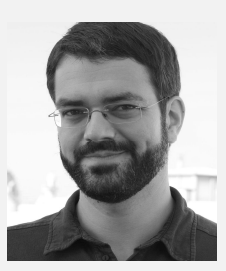

IMPRINT: Owner: Austrian Academy of Sciences; Legal person under public law (BGBI. 569/1921 i.d.F. BGBI. I 130/2003); Dr. Ignaz Seipel-Platz 2, A-1010 Vienna; Editor: Institute of Technology Assessment (ITA); Apostelgasse 23, A-1030 Vienna; www.oeaw.ac.at/ita/en. | Frequency: The ITA Dossiers are published irregularly and publish the research results of the ITA. The ITA Dossiers are published in print in small numbers only and are made available open access to the public via the Internet portal "epub.oeaw": epub.oeaw.ac.at/ita/ita-dossiers | ISSN: 2306-1960 | This work is licensed under a Creative Commons Attribution 4.0 International License: creativecommons.org/licenses/by/4.0/| ITA-Dossier no.44en, July 2019 | epub.oeaw.ac.at/ita/ita-dossiers/ita-dossier044en.pdf | @ (c) Co-authors: Schaber, F., Peissl, W. 